\title{
Aspectos e peculiaridades da produção comercial de mamão (Carica papaya Linnaeus) no Brasil: estratégias para o futuro da cultura
}

\author{
Aspects and peculiarities of the commercial production of papaya (Carica papaya Linnaeus) in
}

\author{
Brazil: strategies for the future of culture
}

Aspectos y peculiaridades de la producción comercial de papaya (Carica papaya Linnaeus) en

Brasil: estrategias para el futuro de la cultura

Suélen Serafini

ORCID: https://orcid.org/0000-0001-5793-2464 Universidade do Estado de Santa Catarina, Brasil E-mail: suelen_serafini@hotmail.com Junior Gonçalves Soares ORCID: https://orcid.org/0000-0001-6342-2479 Universidade do Estado de Santa Catarina, Brasil E-mail: junioragr2009@hotmail.com

Fernanda Picoli

ORCID: https://orcid.org/0000-0003-1631-9430 Universidade do Estado de Santa Catarina, Brasil E-mail: picoli.zootecnista@hotmail.com

Andréia Zilio Dinon

ORCID: https://orcid.org/0000-0002-0676-5050 Universidade do Estado de Santa Catarina, Brasil E-mail: andreia.dinon@udesc.br

Weber da Silva Robazza ORCID: https://orcid.org/0000-0002-7995-8777 Universidade do Estado de Santa Catarina, Brasil E-mail: weber.robazzi@udesc.br

Alexandre Tadeu Paulino

ORCID: https://orcid.org/0000-0001-7076-2797 Universidade do Estado de Santa Catarina, Brasil E-mail: alexandre.paulino@udesc.br

\begin{abstract}
Resumo
O Brasil está entre os principais países produtores e exportadores de mamão (Carica papaya Linnaeus). O mamão é um dos frutos mais importantes na economia e alimentação brasileira, com inúmeras possibilidades industriais e de aplicações nutricionais, farmacológicas e medicinais. Contudo, sua produção no país apresenta aspectos particulares, os quais influenciam as pesquisas científicas sobre o fruto, bem como o mercado consumidor nacional e mundial. Este estudo consiste de uma revisão bibliográfica sobre aspectos e peculiaridades da produção de mamão no Brasil. Foi incluído um breve histórico do mamão; características gerais da planta mamoeiro e do fruto mamão; características de consumo e aplicabilidades industriais do fruto; produção comercial no Brasil; principais cultivares híbridas utilizadas e fatores de risco para a produção, especialmente doenças virais de impacto econômico; aspectos do melhoramento genético do mamoeiro no Brasil; as limitações da transgenia no país e novas estratégias sugeridas. A partir do conjunto de informações deste estudo, são consideradas necessárias pesquisas aplicadas sobre novas tecnologias para a manutenção da produtividade do mamão no Brasil. Para tanto, sugere-se a realização de pesquisas genéticas sobre a hibridização das cultivares comerciais utilizadas com variedades selvagens de mamoeiros da América do Sul e/ou América Central.
\end{abstract}

Palavras-chave: C. papaya L.; Cultivares híbridas; Estratégias; Transgenia.

\begin{abstract}
Brazil is among the main producing and exporting countries of papaya (Carica papaya Linnaeus). Papaya is one of the most important fruits in the Brazilian economy and food, with countless industrial possibilities and nutritional, pharmacological and medicinal applications. However, its production in the country has particular aspects, which influence scientific research on the fruit, as well as the national and world consumer market. This study consists of a literature review on aspects and peculiarities of papaya production in Brazil. A brief history of papaya was included; general characteristics of the papaya plant and the papaya fruit; consumption characteristics and industrial
\end{abstract}


applicability of the fruit; commercial production in Brazil; main hybrid cultivars used and risk factors for production, especially viral diseases of economic impact; aspects of the genetic improvement of papaya in Brazil; the limitations of transgenics in the country and new strategies suggested. From the set of information in this study, applied research on new technologies to maintain papaya productivity in Brazil is considered necessary. Therefore, it is suggested to carry out genetic research on the hybridization of commercial cultivars used with wild papaya varieties from South America and/or Central America.

Keywords: C. papaya L.; Hybrid cultivars; Strategies; Transgenics.

\section{Resumen}

Brasil se encuentra entre los principales países productores y exportadores de papaya (Carica papaya Linnaeus). La papaya es una de las frutas más importantes de la economía y la alimentación brasileñas, con innumerables posibilidades industriales y aplicaciones nutricionales, farmacológicas y medicinales. Sin embargo, su producción en el país tiene aspectos particulares, que inciden en la investigación científica sobre la fruta, así como en el mercado consumidor nacional y mundial. Este estudio consiste en una revisión de la literatura sobre aspectos y peculiaridades de la producción de papaya en Brasil. Se incluyó una breve historia de la papaya; características generales de la planta de papaya y del fruto de papaya; características de consumo y aplicabilidad industrial de la fruta; producción comercial en Brasil; principales cultivares híbridos utilizados y factores de riesgo para la producción, especialmente enfermedades virales de impacto económico; aspectos del mejoramiento genético de la papaya en Brasil; las limitaciones de los transgénicos en el país y las nuevas estrategias sugeridas. A partir del conjunto de información de este estudio, se considera necesaria la investigación aplicada sobre nuevas tecnologías para mantener la productividad de la papaya en Brasil. Por tanto, se sugiere realizar investigación genética sobre la hibridación de cultivares comerciales utilizados con variedades silvestres de papaya de Sudamérica y/o Centroamérica.

Palabras clave: C. papaya L.; Cultivares híbridos; Estrategias; Transgénicos.

\section{Introdução}

O mamão é o fruto da planta mamoeiro, espécie Carica papaya Linnaeus (C. papaya L.) (Chávez-Pesqueira \& Núñez-Farfán, 2017). No Brasil, o mamão é uma das culturas mais importantes da fruticultura comercial. Economicamente, o país destaca-se como um dos principais produtores e exportadores mundiais do fruto (EMBRAPA, 2019; FAOSTAT, 2021; IBGE, 2021; TRIDGE, 2021). O interesse sobre a produção nacional e mundial de mamão tem se destacado para além do setor agroindustrial alimentício, devido às possibilidades científicas de aplicações farmacológicas e medicinais de compostos fitoquímicos obtidos a partir da planta mamoeiro e do fruto mamão (Venturini et al., 2012; Boshra \& Tajul, 2013; Dias et al., 2015; Barroso et al., 2016; Prasetya et al., 2018; Carvalho et al., 2020).

A percepção de novos cenários industriais e econômicos a serem explorados pelo Brasil, desperta a necessidade de compreender o perfil da produção de mamão no país, especialmente as suas atuais limitações. No Brasil, a produção comercial de mamão concentra-se principalmente nas Regiões Nordeste e Sudeste (EMBRAPA, 2019; IBGE, 2021) e é dependente de poucas cultivares híbridas de genótipos dos grupos Solo e Formosa, o que implica na baixa diversidade genética das plantas (Vivas et al., 2017; Carvalho et al., 2020). Esta baixa variabilidade genética está sujeita aos efeitos das condições edafoclimáticas e à incidência de pragas e doenças fúngicas e virais, fatores que afetam qualitativamente e quantitativamente a produção de mamão no país (Souza Júnior, Nickel \& Gonsalves, 2005; EMBRAPA, 2013; Vivas et al., 2017; Carvalho et al., 2020).

Dentre tais limitações, a ocorrência de doenças virais é um dos principais gargalos na fruticultura do mamão (Souza Júnior, Nickel \& Gonsalves, 2005; ISAAA, 2021). Em estudos de melhoramento genético internacionais, em muitos países produtores de mamão é comum a incorporação de genes de resistência (transgenia) para amenizar a problemática das doenças virais em mamoeiros e seus frutos (Souza Júnior, Nickel \& Gonsalves, 2005; ISAAA, 2021). Porém, no Brasil enfrenta-se discordância com os protocolos internacionais, visto que são adicionados em conjunto genes de resistência a antibióticos e estes não são liberados no país (Souza Júnior, Nickel \& Gonsalves, 2005; Meissner Filho, 2011; ISAAA, 2021). Deste modo, torna-se necessário atentar para a minimização de impactos sobre a produtividade brasileira de mamão com uso tecnologias e estratégias de melhoramento genético diferenciadas (Meissner Filho, 2011; Chávez-Pesqueira \& Núñez-Farfán, 2017). 
O objetivo com este estudo foi realizar uma revisão bibliográfica sobre aspectos e peculiaridades da produção de mamão no Brasil. Esta revisão abrange um apanhado histórico do mamão; características gerais da planta mamoeiro e do fruto mamão; características de consumo e aplicabilidades industriais do fruto; produção comercial no Brasil; principais cultivares híbridas utilizadas e fatores de risco para a produção; aspectos do melhoramento genético do mamoeiro no Brasil; as limitações da transgenia no país e novas estratégias sugeridas.

\section{Metodologia}

Este estudo é uma pesquisa de revisão bibliográfica de natureza qualitativa, elaborada a partir de publicações e discussões de outros autores sobre o tema proposto (Köche, 2011; Estrela, 2018). Para o levantamento de informações e conclusões foram realizadas pesquisas em plataformas governamentais de divulgação e controle da produção e comércio do fruto; pesquisas em plataformas governamentais de controle de pesquisas genéticas; análises críticas de estudos científicos e técnicos; dentre outros, considerando fontes nacionais e internacionais. O período total de cobertura das informações analisadas foi de 68 anos (1953 a 2021), com 35,3\% de predominância de informações coletadas e publicadas nos últimos cinco anos. Como critério para inclusão e/ou exclusão de informações foi considerado a confiabilidade dos órgãos de divulgação e a publicação de estudos em revistas científicas qualificadas.

\section{Revisão}

\subsection{Histórico do Mamão}

C. papaya L. pertence à família Caricaceae originária da África Tropical e a sua dispersão para a América Central ocorreu há cerca de 35 milhões de anos (Carvalho \& Renner, 2012). Sementes dormentes de frutos podem ter chegado à Mesoamérica em ilhas de vegetação flutuante, carregadas pelas correntes oceânicas (Carvalho \& Renner, 2012). Considera-se que o mamoeiro doméstico seja uma planta endêmica da América Central, especificamente da região localizada entre o Sul do México e a Guatemala (Carvalho \& Renner, 2012). A planta foi cultivada por povos nativos desde o Sul do México ao istmo do Panamá (Chávez-Pesqueira \& Núñez-Farfán, 2017).

Membros da família Caricaceae provenientes da América Central chegaram à América do Sul entre 27 a 19 milhões de anos atrás, quando a ponte terrestre do Panamá já havia começado a se formar e permitiu o contato territorial com a América do Sul (Carvalho \& Renner, 2012). Contudo, atribuiu-se a disseminação do mamão para além da Mesoamérica aos espanhóis no século XVI (Carvalho \& Renner, 2014). O mamão foi introduzido pelos espanhóis em 1521 na ilha Hispaniola, hoje Haiti e São Domingos. Desta ilha, espalhou-se para outras ilhas das Índias Ocidentais, como a Jamaica, posteriormente para a Venezuela, Argentina e Brasil (Chávez-Pesqueira \& Núñez-Farfán, 2017). A adaptação natural do mamoeiro às regiões de clima tropical e subtropical tem permitido o seu cultivo em todo o território brasileiro desde 1587 (Venturini et al., 2012).

\subsection{Características Gerais da Planta}

As plantas de mamoeiro apresentam tronco com uma única haste simples, formada por um caule semi-herbáceo, oco, cilíndrico de 10 a $30 \mathrm{~cm}$ de diâmetro, fistuloso, ereto, de coloração verde-clara no ápice e verde-grisácea à acinzentada na base. O mamoeiro cresce rapidamente e pode atingir até 2,5 m de altura (Medina et al., 1989; Dantas \& De Castro Neto, 2000; Barroso et al., 2016). O tronco contém folhas na região apical, dispostas de forma espiralada. As folhas são grandes, partidas em lóbulos, nervadas, alternadas, de coloração verde-clara mate na face superior e verde-brancacento pálido na face inferior, cujos tamanhos variam de 20 a $60 \mathrm{~cm}$ de comprimento (Medina et al., 1989; Dantas \& De Castro Neto, 2000). O sistema radicular do mamoeiro é pivotante e pode se desenvolver até duas vezes a altura da planta e explorar o solo em uma 
profundidade de até 1 m (Luna, 1986; Dantas \& De Castro Neto, 2000).

As flores do mamoeiro podem ser divididas basicamente em três tipos bem diferenciados: flor pistilada ou feminina típica, flor hermafrodita (pentandra, intermediária e elongata) e flor estaminada ou masculina típica. Frutos de interesse comercial são gerados pelas flores dos tipos pistilada e/ou hermafrodita elongata (Dantas \& De Castro Neto, 2000). Em termos genéticos, o mamoeiro é a quinta planta com flor a ter seu genoma sequenciado (Kanchana-Udomkan, Ford \& Drew, 2014). Esta planta é diploide com $2 \mathrm{n}=2 \mathrm{x}=18$ cromossomos, ou seja, possui número básico de cromossomos haploides ou genoma $\mathrm{n}$ $=9($ Storey, 1953) e o tamanho do genoma em torno de 372 milhões de pares de bases (Mbp) (Arumuganathan \& Earle, 1991).

\subsection{Características e Propriedades do Fruto, Consumo e Aplicabilidades Industriais}

De modo geral, o mamão é um fruto tipo baga, descrito como ovoide, esférico ou piriforme dependendo do tipo de flor que o gerou. Este fruto é carnudo e de porte variado, com tamanhos variando entre pequenos até muito grandes. Contém polpa macia, densa e aromática, cujas cores variam com o amadurecimento do amarelo ao vermelho. A casca do mamão é lisa e fina, verde quando colhida, tornando-se gradualmente amarela ou laranja durante o amadurecimento (Badillo, 1993; Dantas \& De Castro Neto, 2000; Barroso et al., 2016). A cavidade interna do fruto contém sementes pretas com sabor picante, as quais são revestidas por uma substância protetora mucilaginosa, denominada sarcotesta (Dias et al., 2015; Barroso et al., 2016). A composição percentual de um mamão C. papaya L. típico pode variar de 12 a 25,3\% de casca, 69,3 a 79,5\% de polpa e 5,4 a 8,5\% de sementes (FAO, 2003).

Variações em características visuais e organolépticas do mamão podem ocorrer em função de diferenciações entre grupos da espécie, suas variedades e cultivares (FAO, 2003). No Brasil, as principais variedades e cultivares híbridas são dos grupos Solo e Formosa (Vivas et al., 2017; Carvalho et al., 2020). No grupo Solo encontra-se a maioria das cultivares de mamoeiros utilizadas no Brasil e no mundo, este grupo apresenta frutos pequenos, com peso de 350 a $600 \mathrm{~g}$ e de polpa avermelhada. O grupo Formosa é composto por mamoeiros que apresentam frutos de tamanho médio, com peso de 800 a 1.100 g e de polpa laranja-avermelhada (EMBRAPA, 2003; Reis et al., 2015).

A polpa do mamão é comumente consumida pelo ser humano, preferencialmente in natura, após a maturação do fruto. Além disto, não apenas a polpa, mas também a casca e sementes do fruto e folhas da planta são utilizadas pelas indústrias alimentícias, farmacológicas e medicinais como matéria-prima para diversos produtos e subprodutos: geleias, sucos, cosméticos, cicatrizantes, dentre outros (Venturini et al., 2012; Boshra \& Tajul, 2013; Dias et al., 2015; Barroso et al., 2016; Prasetya et al., 2018; Carvalho et al., 2020). Além de produzido em grande quantidade, o mamão é um dos frutos mais consumidos pelos brasileiros, ocupando a quinta posição no ano de 2018 com o consumo per capita de 1,8 kg ano ${ }^{-1}$ (Moda, Mendes \& Camargo, 2021). Este fruto é rico em vitaminas A, B e C, carboidratos, proteínas, bem como substâncias de interesse farmacológico, como compostos fenólicos, alcaloides (carpaína e pseudocarpaína), enzimas proteolíticas (papaína e quimiopapaína) e derivados de glicosinolatos (Venturini et al., 2012; Boshra \& Tajul, 2013; Dias et al., 2015; Barroso et al., 2016; Prasetya et al., 2018; Carvalho et al., 2020).

\subsection{Produção Comercial de Mamão no Brasil}

Segundo os mais recentes dados disponíveis, o Brasil foi o terceiro maior produtor mundial de mamão no ano de 2019, atrás de Índia e República Dominicana, respectivamente (FAOSTAT, 2021). A produção mundial de mamão em 2019 atingiu 13,74 milhões $\mathrm{t} \mathrm{ano}^{-1}$, neste cenário o Brasil respondeu por 1,16 milhões $\mathrm{t}$ ano-1 ${ }^{-1}$, aproximadamente $8,4 \%$ do total produzido (FAOSTAT, 2021). Também se observa que o Brasil é um importante exportador deste fruto. No ano de 2020, o Brasil respondeu por 28,45\% da exportação mundial, atrás apenas de México com 29,19\% (TRIDGE, 2021). Neste mesmo 
ano, Alemanha, Portugal e Espanha destacaram-se como os principais destinos de exportação do fruto pelo Brasil (TRIDGE, 2021).

Frente aos demais países produtores comerciais de mamão, a vantagem da produção deste fruto pelo Brasil está relacionada com a dimensão da área territorial produzida e da possibilidade de cultivo e produtividade da planta durante todas as estações do ano, nas zonas de produção. Isto garante a possibilidade do fornecimento regular e contínuo de mamão para o mercado consumidor interno e externo (EMBRAPA, 2019). As áreas de cultivo de mamão no Brasil apresentam renovação dos pomares em períodos máximos de três anos (Dantas \& De Castro Neto, 2000).

Dados nacionais do ano de 2019 sobre a produção de mamão no Brasil indicaram uma área total colhida de 27.556 ha (IBGE, 2021). As principais regiões produtoras foram Nordeste e Sudeste, com 54,9\% e 40,3\% da produção, respectivamente (IBGE, 2021). Os estados que mais se destacaram em produção de mamão foram Espírito Santo (403.278 t ano em $^{-1} 6.874$ ha), Bahia (390.075 t ano ${ }^{-1} \mathrm{em} 9.638$ ha) e Ceará (118.717 t ano ${ }^{-1} \mathrm{em} 1.992$ ha) (IBGE, 2021). Nestes estados, os principais polos produtores estão localizados no Extremo Sul da Bahia e no Norte do Espírito Santo (EMBRAPA, 2019). No entanto, os polos de produção deste fruto no país estão continuamente em estudo para serem ampliados, a partir do desenvolvimento de tecnologias agrícolas e estudos de adaptação da planta para diferentes regiões. A facilidade de seu cultivo, o amplo mercado consumidor, a diversidade de usos e aplicações industriais e o bom preço praticado são fatores importantes que estimulam a busca por altos índices na produção (EMBRAPA, 2019).

\subsection{Cultivares Híbridas de Mamoeiros no Brasil}

A domesticação do mamoeiro iniciou na Mesoamérica (Carvalho \& Renner, 2012), mas atualmente existe uma gama relativa de cultivares híbridas da planta na maioria das regiões tropicais e subtropicais do mundo, diferindo especialmente quanto a características de tamanho, cor e sabor do fruto (Moore, 2014). A domesticação foi contínua, o que foi crucial para atender à demanda de melhoria da produtividade e da qualidade desta cultura, principalmente devido à expansão produtiva do mamão (Tang, Sezen \& Paterson, 2010; Carvalho et al., 2020). Além disto, é possível acrescentar que a domesticação associada ao melhoramento genético antrópico por hibridização, ou mesmo por transgenia, visa selecionar características genéticas de interesse nas cultivares. Estas são escolhidas em função da expressão de características agronômicas superiores, resistência a doenças e, principalmente, frutos que atendam às exigências do mercado consumidor, pois este conjunto de características não é obtido com o cultivo de um único genótipo da planta (Reis et al., 2015; Vivas et al., 2017; Carvalho et al., 2020).

Como citado anteriormente, os genótipos de mamoeiros comercialmente cultivados no Brasil pertencem aos grupos Solo e Formosa. A produção brasileira de mamão atual é baseada em uma estreita diversidade genética e limitada a poucas cultivares híbridas (Carvalho et al., 2020). As cultivares híbridas são obtidas a partir de melhoramento genético intra e intergrupos, a partir de cruzamentos entre plantas com características de interesse (Da Luz et al., 2015). As cultivares híbridas produzidas no Brasil do grupo Solo são: Sunrise Solo, Improved Sunrise Solo Line 72/12, Aliança, Golden, Baixinho de Santa Amália, Taiwan, Kapoho Solo, Waimanalo e Higgins. Estas cultivares apresentam produção média de $40 \mathrm{t}^{2}$ ha ano ${ }^{-1} \mathrm{e}$ resistência ao transporte e ao armazenamento, por isso são destinadas principalmente à exportação (EMBRAPA, 2013; Da Luz et al., 2015; Reis et al., 2015). Do grupo Formosa são cultivadas as cultivares: Híbrido F1, Tainung n. ${ }^{\circ} 1$ e Tainung n. ${ }^{\circ}$ 2. Estas cultivares apresentam maior produção média, cerca de $60 \mathrm{t}$ ha $a^{-1}$, porém menor resistência ao transporte e ao armazenamento. Desta forma, são destinadas principalmente ao mercado interno brasileiro (EMBRAPA, 2013; Da Luz et al., 2015; Reis et al., 2015). 


\subsection{Principais Fatores Limitantes para a Produção de Mamão no Brasil}

Esta diversidade genética estreita está sujeita à alta incidência de pragas e doenças, bem como a limitações de tolerância às variações de condições climáticas. Estes fatores comprometem a produtividade e limitam a expansão das áreas cultivadas no Brasil (Carvalho et al., 2020). Dentre os principais agentes causadores de doenças limitantes para o cultivo e produtividade do mamoeiro no Brasil, estão o vírus do mosaico do mamoeiro (Papaya mosaic virus, PMV), o vírus da mancha anelar (Papaya ringspot virus, PRSV) e o vírus da meleira do mamoeiro (Papaya sticky disease virus, PSDV) (Souza Júnior, Nickel \& Gonsalves, 2005; EMBRAPA, 2013; Carvalho et al., 2020).

O PMV reduz a produção e prejudica a qualidade do fruto. Seus principais indícios incluem amarelecimento e enrugamento das folhas mais novas, clareamento das nervuras, mosaico nas folhas e paralisação do crescimento das plantas (EMBRAPA, 2013). O PRSV apresenta maior relevância a nível mundial e é um problema extremamente limitante na produção de mamão além das fronteiras do Brasil (Souza Júnior, Nickel \& Gonsalves, 2005; Chávez-Pesqueira \& NúñezFarfán, 2017; Carvalho et al., 2020). Plantas acometidas pelo PRSV apresentam baixa produtividade e os frutos atingidos podem se tornar imprestáveis para a comercialização. Seus principais indícios são amarelecimento das folhas mais novas, clareamento das nervuras, enrugamento e mosaico nas folhas, redução da lâmina foliar (sintoma conhecido como fio-desapato), aparecimento de estrias oleosas nos pecíolos e outros órgão e aparecimento de anéis necróticos nos frutos (EMBRAPA, 2013). O PSDV apresenta como principal indício a perda por gotejamento do látex (leite) nos frutos (EMBRAPA, 2013).

\subsection{Melhoramento Genético do Mamoeiro no Brasil, Limitações da Transgenia e Novas Estratégias}

Uma das estratégias utilizadas para o melhoramento genético do mamoeiro com o intuito de minimizar o impacto de doenças virais limitantes é a inserção de genes de resistência aos vírus (Souza Júnior, Nickel \& Gonsalves, 2005; KanchanaUdomkan, Ford \& Drew, 2014). Nos protocolos comumente utilizados para o mamoeiro, é comum a inserção de gene de resistência ao vírus específico em conjunto com gene de resistência a antibióticos, além de marcadores moleculares para identificação da eficiência do processo de transgenia (Souza Júnior, Nickel \& Gonsalves, 2005; Kanchana-Udomkan, Ford \& Drew, 2014; ISAAA, 2021). O Brasil, representado pela Empresa Brasileira de Pesquisa Agropecuária (EMBRAPA), participou em 1990 do desenvolvimento de um mamoeiro transgênico resistente ao PRSV em conjunto com a Universidade de Cornell, Estados Unidos da América. O projeto chamou-se Embrapa BioSeg e visava produzir um mamoeiro transgênico, cultivar Sunrise Solo, resistente a uma estirpe brasileira do PRSV (Souza Júnior, Nickel \& Gonsalves, 2005; Meissner Filho, 2011).

Em 2007, após diversos estudos de biossegurança com mamoeiros geneticamente modificados, estes foram cultivados em um campo no Ceará. Durante o desenvolvimento e produção, observou-se a ocorrência do PRSV, mas se verificou que houve um retardo na infecção das plantas transgênicas, assim como sua produção foi cerca de $50 \%$ superior em relação às convencionais (Souza Júnior, Nickel \& Gonsalves, 2005). Estes resultados permitiram concluir que a transgenia pode ser uma possibilidade interessante para a produção comercial de mamão, especialmente para cultivares de exportação.

O projeto Embrapa BioSeg foi finalizado na mesma época e recusada a continuidade da pesquisa, haja vista a incorporação de política na EMBRAPA em não investir em produtos que contenham genes de resistência a antibióticos, como é comum em estudos de geração de plantas transgênicas (Souza Júnior, Nickel \& Gonsalves, 2005; Meissner Filho, 2011). Atualmente, para novos produtos transgênicos, recomenda-se que eles não possuam esses genes, pois a presença dos mesmos poderia dificultar sua liberação comercial pela Comissão Técnica Nacional de Biossegurança (CTNBio) e demais órgãos regulamentadores (Meissner Filho, 2011). Deste modo, até o ano de 2020, não houve cultivares geneticamente modificados de mamoeiros liberados para cultivo no Brasil, ou mesmo processos em tramitação apresentados à CTNBio (CTNBio, 2021). 
Tendo em vista as dificuldades na liberação de mamoeiros transgênicos no Brasil, outras possibilidades podem e devem ser sugeridas e aplicadas. Assim como, buscar estratégias para melhor explorar o mercado de exportação europeu que apresenta restrições para produtos transgênicos, já atendido pelo Brasil (TRIDGE, 2021).

Outra forma de controlar doenças virais dentro do melhoramento genético é a geração de híbridos selecionados para a resistência, por meio do cruzamento entre plantas domesticadas resistentes. Neste sistema, buscam-se fontes de resistência entre parentais do mamoeiro cultivado, intra ou intergrupos. Depois, testa-se a produção de plantas pré-imunizadas com estirpes fracas do vírus. Todavia, esta estratégia é dita como não muito eficiente, pois em pouco tempo ocorre a diluição genética da resistência pela semelhança do genótipo das plantas (Meissner Filho, 2011).

Deste modo, uma possibilidade inovadora seria a seleção de populações selvagens de mamoeiros que podem ser encontrados na Mesoamérica para a geração de novos híbridos. Estudos sugerem que estes mamoeiros silvestres possuem alta diversidade genética em comparação com o mamoeiro doméstico, assim como maior resistência, a qual pode ser incorporada ao genoma de mamoeiros cultivados, originando novas cultivares comerciais (Chávez-Pesqueira \& Núñez-Farfán, 2017).

\section{Considerações Finais}

Apesar do impacto da estreita variedade genética das cultivares híbridas comercias cultivadas no Brasil sobre a produção de mamão, há possibilidades dentro do melhoramento genético para minimizar o impacto de doenças virais e garantir o aumento da produtividade. Estudos para o desenvolvimento do mamão transgênico têm sido desenvolvidos. No entanto, devido a desafios relativos às barreiras éticas e ambientais relacionadas à transgenia, observa-se que a resistência do mamoeiro aos vírus pode ser adquirida por meio de hibridização de cultivares comerciais com variedades selvagens de mamoeiros da América do Sul e/ou América Central. Deste modo, sugere-se o desenvolvimento de estudos futuros que abordem a manutenção de aspectos produtivos e características desejáveis em frutos, já existentes nos mamoeiros comerciais, em conjunto com a resistência verificada em plantas silvestres.

\section{Referências}

Arumuganathan, K. \& Earle, E. D. (1991). Nuclear DNA content of some important plant species. Plant Molecular Biology Reporter, 9, $208-218$.

Badillo, V. M. (1993). Caricaceae: segundo esquema. Revista de la Facultad de Agronomía de la Universidad Central de Venezuela, 43, 1-111.

Barroso, P. T. W., De Carvalho, P. P., Rocha, T. B., Pessoa, F. L. P., Azevedo, D. A. \& Mendes, M. F. (2016). Evaluation of the composition of Carica papaya L. seed oil extracted with supercritical $\mathrm{CO}_{2}$. Biotechnology Reports, 11, 110-116.

Boshra, V. \& Tajul, A.Y. (2013). Papaya - an innovative raw material for food and pharmaceutical processing industry. Health and the Environment Journal, $1(4), 68-75$.

Carvalho, E. de M. L., Reis, R. C., Borges, V. P., Ledo, C. A. da S., Araújo, E. da S. \& Dantas, J. L. L. (2020). Physicochemical and sensory properties of papaya fruits of elite lines and hybrids. Semina: Ciências Agrárias, 41(1), 121-130.

Carvalho, F. A. \& Renner, S. S. (2012). A dated phylogeny of the papaya family (Caricaceae) reveals the crop's closest relatives and the family's biogeographic history. Molecular Phylogenetics and Evolution, 65(1), 46-53.

Carvalho, F. A. \& Renner, S. S. (2014). The phylogeny of the Caricaceae in 'Genetics and genomics of papaya'. Springer.

Chávez-Pesqueira, M. \& Núñez-Farfán, J. (2017). Domestication and genetics of papaya: a review. Frontiers in Ecology and Evolution, 5 , 155.

CTNBio - Comissão Técnica Nacional de Biossegurança (2021). Relatórios anuais: 2020. https://ctnbio.mctic.gov.br/relatorios-anuais

Da Luz, L. N., Pereira, M. G., Barros, F. R., Barros, G. de B. \& Ferreguetti, G. A. (2015). Novos híbridos de mamoeiro avaliados nas condições de cultivo tradicional e no semiárido brasileiro. Revista Brasileira de Fruticultura, 37(1), 159-171.

Dantas, J. L. L. \& De Castro Neto, M. T. (2000). Aspectos botânicos e fisiológicos em 'Mamão - produção: aspectos técnicos'. Embrapa Comunicação para Transferência de Tecnologia.

Dias, M. A., Dias, D. C. F. dos S., Borges, E. E. de L. \& Dias, L. A. dos S. (2015). Qualidade e compostos fenólicos em sementes de mamão alterados pela colheita e maturação dos frutos. Ciência Rural, 45(4), 737-743. 
Research, Society and Development, v. 10, n. 12, e544101220551, 2021 (CC BY 4.0) | ISSN 2525-3409 | DOI: http://dx.doi.org/10.33448/rsd-v10i12.20551

EMBRAPA - Empresa Brasileira de Pesquisa Agropecuária (2003). Mamão: o produtor pergunta, a Embrapa responde. Embrapa Informação Tecnológica.

EMBRAPA - Empresa Brasileira de Pesquisa Agropecuária (2013). Mamão: o produtor pergunta, a Embrapa responde. Embrapa.

EMBRAPA - Empresa Brasileira de Pesquisa Agropecuária (2019). Plano estratégico para a cultura do mamoeiro 2017-2021. Embrapa Mandioca e Fruticultura.

Estrela, C. (2018). Metodologia científica: ciência, ensino, pesquisa. Artes Médicas.

FAO - Food and Agriculture Organization of the United Nations (2003). Pawpaw: post-harvest operation. Instituto Tecnológico de Veracruz.

FAOSTAT - Food and Agriculture Organization of the United Nations (2021). Crops: 2019. https://www.fao.org/faostat/en/\#data/QC/

IBGE - Instituto Brasileiro de Geografia e Estatística (2021). Produção agrícola municipal - PAM: 2019. https://www.ibge.gov.br/es tatisticas/economicas/agricultura-e-pecuaria/9117-producao-agricola-municipal-culturas-temporarias-e-permanentes.html?=\&t=o-que-e

ISAAA - International Service for the Acquisition of Agri-Biotech Applications (2021). Papaya (Carica papaya) GM events. https://www.isaaa.org/gmapprovaldatabase/crop/default.asp?CropID=11\&Crop=Papaya

Kanchana-Udomkan, C., Ford, R. \& Drew, R. (2014). Molecular markers in papayas in 'Genetics and genomics of papaya'. Springer.

Köche, J. C. (2011). Fundamentos de metodologia científica: teoria da ciência e iniciação à pesquisa. Vozes.

Luna, J. V. U. (1986). Variedades de mamoeiros. Informe Agropecuário, 13(134), 14-18.

Medina, J. C., Bleinroth, E. W., Sigrist, J. M. M., De Martin, Z. J., Nisida, A. L. A. C., Baldini, V. L. S., Leite, R. S. S. F. \& Garcia, A. E. B. (1989). Mamão: cultura, matéria-prima, processamento e aspectos econômicos. Ital.

Meissner Filho, P. E. (2011). Mamoeiro transgênico no Brasil: resultados obtidos e legislação para sua liberação em 'Simpósio do papaya brasileiro inovação e sustentabilidade: anais'. Embrapa Mandioca e Fruticultura.

Moda, L., Mendes, A. R. \& Camargo, I. (2021). O que mudou no consumo brasileiro de frutas e hortaliças nos últimos anos?: renda, conveniência e pandemia alteram os hábitos no Brasil. Brasil Hortifruti, 20(209), 10-17.

Moore, P. H. (2014). Phenotypic and genetic diversity of papaya in 'Genetics and genomics of papaya'. Springer.

Prasetya, A. T., Mursiti, S., Maryan, S. \& Jati, N. K. (2018). Isolation and identification of active compounds from papaya plants and activities as antimicrobial. IOP Conference Series: Materials Science and Engineering, 349, 012007.

Reis, R. C., Viana, E. de. S., De Jesus, J. L., Dantas, J. L. L. \& Lucena, R. S. (2015). Caracterização físico-química de frutos de novos híbridos e linhagens de mamoeiro. Pesquisa Agropecuária Brasileira, 50(3), 210-217.

Souza Júnior, M. T., Nickel, O. \& Gonsalves, D. (2005). Development of virus resistant transgenic papayas expressing the coat protein gene from a Brazilian isolate of Papaya ringspot virus. Fitopatologia Brasileira, 30(4), 357-365.

Storey, W. B. (1953). Genetics of the papaya. Journal of Heredity, 44(2), 70-78.

Tang, H., Sezen, U. \& Paterson, A. H. (2010). Domestication and plant genomes. Current Opinion in Plant Biology, 13(2), $160-166$.

TRIDGE (2021). Papaya: 2019-2020. https://www.tridge.com/intelligences/papaya

Venturini, T., Benchimol, L. R., Bertuol, D. A., Da Rosa, M. B. \& Meili L. (2012). Estudo da secagem e extração de sementes de mamão (Carica papaya L.). Revista Eletrônica em Gestão, Educação e Tecnologia Ambiental, 5(5), 950-959.

Vivas, M., Da Silveira, S. F., Vivas, J. M. S., Dos Santos, P. H. D., Carvalho, B. M., Daher, R. F. \& Pereira, M. G. (2017). Phenotypic characterization of papaya genotypes to determine powdery mildew resistance. Crop Breeding and Applied Biotechnology, 17(3), 198-205. 